\title{
A Comparative Study on Pharmacokinetics of Tricin, a Flavone from Gramineous Plants with Antiviral Activity
}

\section{Galina I. Solyanik¹, Oleg S. Zulphigarov², Iryna V. Prokhorova1, Olga N. Pyaskovskaya1, Denis L. Kolesnik ${ }^{1}$, Viktor P. Atamanyuk ${ }^{2}$}

${ }^{1}$ Laboratory of Molecular and Cellular Mechanisms of Metastasis, R.E. Kavetsky Institute of Experimental Pathology, Oncology and Radiobiology of NASU, Kyiv, Ukraine

${ }^{2}$ SMC Ecopharm Ltd., Kyiv, Ukraine

Email: oncom@online.ua

How to cite this paper: Solyanik, G.I., Zulphigarov, O.S., Prokhorova, I.V., Pyaskovskaya, O.N., Kolesnik, D.L. and Atamanyuk, V.P. (2021) A Comparative Study on Pharmacokinetics of Tricin, a Flavone from Gramineous Plants with Antiviral Activity. Journal of Biosciences and Medicines, 9, 76-91.

https://doi.org/10.4236/jbm.2021.92008

Received: January 19, 2021

Accepted: February 20, 2021

Published: February 23, 2021

Copyright $\odot 2021$ by author(s) and Scientific Research Publishing Inc. This work is licensed under the Creative Commons Attribution International License (CC BY 4.0).

http://creativecommons.org/licenses/by/4.0/

\section{(c) (i) Open Access}

\begin{abstract}
Tricin (and tricin containing plant extracts) has been shown to exert a pronounced antiviral activity, high radical scavenging activity and is favored for its safety profile. In the present study we have analyzed the pharmacokinetics of tricin after a single intravenous and oral administration to Wistar rats of an ethanol extract of Calamagrostis Adans and Deschampsia Beauv plants (test agent) at different doses. Tricin concentrations in blood plasma and blood cells were measured at different time points. Two-compartment (for intravenous injection) and one compartment (for oral administration) models were used for the analysis of tricin pharmacokinetics. The results showed that the pharmacokinetics of tricin after intravenous injection of test agent has a pronounced biphasic character, is well described by a two-compartment pharmacokinetic model, and is characterized by non-linear dose-dependence. The pharmacokinetics of tricin administered orally is characterized by a high rate of absorption from the gastrointestinal tract into the blood and rather slow elimination, which leads to a large volume of distribution in the body and a fairly high bioavailability. The obtained results indicate the advantages of the oral route of administration over the intravenous route.
\end{abstract}

\section{Keywords}

Polyphenolic Compounds, Tricin, Pharmacokinetics, Bioavailability

\section{Introduction}

Despite the active synthesis of medicinal preparations, plants remain a rich 
source of biologically active substances, among which polyphenolic compounds occupy a special place. They constitute the largest group of secondary metabolites that play an important role in the development of plants and their protection from the action of both physical factors (environmental factors) and plant pathogens and insects.

For many centuries plants and their extracts have been widely used by mankind; however, large-scale studies of the spectrum of their pharmacological activity began in the middle of the last century. Since then, it has been demonstrated that flavonoids exhibit pronounced activities (antioxidant [1], anti-inflammatory [2] [3], antibacterial [4], antiviral [5] [6], and anticancer ones [7] [8] [9]), and also possess the ability to reduce the risk of developing certain chronic diseases [10] [11].

Due to the increased demand for antiviral drugs over the past few decades, the search and research of antiviral polyphenolic compounds have intensified. Among the latest, tricin attracted particular interest due to its unique biological properties over other flavonoids [12] [13]. Tricin and tricin containing plant extracts have been shown to exert a pronounced activity against human cytomegalovirus [14] [15] [16] [17], and an ability to suppress replication of the hepatitis B virus [18] and seasonal A and B viruses [19]. It should be noted that along with the antiviral activity tricin exhibits higher radical scavenging activity in comparison with commonly used polyphenolic compounds such as quercetin, myricetin, and catechin [20]. Tricin also is favored for its safety profile, as it lacked any genotoxic properties, the manifestation of which compromised the clinical usefulness of many flavonoids (in particular, genistein and quercetin) [21].

In vitro and in vivo studies of a tricin-containing alcoholic extract from the green parts of wild cereal plants Gramineae, genera Calamagrostis Adans and Deschampsia Beauv, have demonstrated its pronounced antiviral activity against a wide range of DNA and RNA viruses (such as viruses of herpes, hepatitis, papillomaviruses, human immunodeficiency virus, influenza, and acute respiratory infections) [22] [23] [24]. It is also able to induce the synthesis of endogenous $\alpha$ and $\gamma$-interferons up to their physiologically active levels, therefore increasing the body's nonspecific resistance to viral and bacterial infections.

It is known that the effectiveness of the pharmacological action of medicinal preparations depends significantly on their bioavailability, which is considered maximal when they are administered intravenously [25]. For extravascular administrations (including oral), the bioavailability of drugs (even with good water solubility) is usually much lower. It is well known that the most polyphenols (including tricin) are characterized by poor aqueous solubility and low dissolution rates, which not only significantly limits the creation of injectable dosage forms on their basis, but also results in their low in vivo bioavailability during oral administrations [26]. The development of effective non-toxic (or low-toxic) vehicle of polyphenols is one of the ways to improve their solubility and bioavailability. 
Studies have shown the possibility of using water and ethanol mixtures to dissolve the tricin [27].

In the present study, we have analyzed the pharmacokinetics of tricin (using water and ethanol mixtures as a vehicle) extracted from Calamagrostis Adans and Deschampsia Beauv plants after a single intravenous and oral administration to Wistar rats. The peculiarities of tricin distribution in the body and its elimination from the body make it possible to choose the route of administration and develop an optimal scheme of use.

\section{Materials and Methods}

\subsection{Test Agent}

For pharmacokinetic studies, an ethanol extract of tricin-containing plants $\mathrm{Ca}$ lamagrostis Adans and Deschampsia Beauv (mass ratio 1:1) was used; it was evaporated and polyethylene glycol 400 was used to resolute hydrophilic-lipophilic substances. As a result, $1 \mathrm{ml}$ of solution (hereinafter test agent) for injection and oral administration contained $8 \mathrm{mg}$ of active ingredients, ethanol (less than $50 \%$ ), and $10 \%$ of polyethylene glycol 400 .

The active molecular components of the test agent are flavones and flavone glycosides forming complexes: [tricin, tricin-7-O or 8-C glycoside]: [luteolin-7-O or 8-C glycoside]: [apigenin, apigenin-7-O glycoside or 8 -C glycoside] in the amount of $7.4 \%-8.5 \%$ of the dry residue weight (3:4:1 ratio) (Figure 1).

Determination of the phytochemical content of the test agent was carried out using high-performance liquid chromatography with diode array detection (HPLC, UPLC-PDA); gas chromatography-mass spectrometry-electron impact ionization (GC-MS); high-performance liquid chromatography-electrospray ionization-mass spectrometry (UPLC-MC/MC); by nuclear magnetic resonance (NMR).<smiles>[R]c1cc(-c2oc3c([R8])c([R])c([R6])c([R5])c3c(=O)c2[R7])cc([R4])c1[R]</smiles>

Figure 1. Structure of active molecular components of ethanol extract of Calamagrostis Adans and Deschampsia Beauv plants, where: $\mathrm{R}_{3}, \mathrm{R}_{5}, \mathrm{R}_{7}=\mathrm{OH} ; \mathrm{R}_{2}, \mathrm{R}_{4}=\mathrm{OMe} ; \mathrm{R}_{1}, \mathrm{R}_{6}, \mathrm{R}_{8}=$ $\mathrm{H}$ (for tricin); $\mathrm{R}_{1}=\mathrm{H} ; \mathrm{R}_{2}, \mathrm{R}_{4}=\mathrm{OMe} ; \mathrm{R}_{3}, \mathrm{R}_{5}, \mathrm{R}_{7}=\mathrm{O}$-glycoside or $\mathrm{OH} ; \mathrm{R}_{6}, \mathrm{R}_{8}=\mathrm{H}$ or C-glycoside (for tricin glycosides); $\mathrm{R}_{2}, \mathrm{R}_{3}, \mathrm{R}_{5}, \mathrm{R}_{7}=\mathrm{OH} ; \mathrm{R}_{1}, \mathrm{R}_{4}, \mathrm{R}_{6}, \mathrm{R}_{8}=\mathrm{H}$ (for luteolin); $\mathrm{R}_{1}$ $=\mathrm{H} ; \mathrm{R}_{2}, \mathrm{R}_{3}, \mathrm{R}_{5}, \mathrm{R}_{7}=\mathrm{O}$-glycoside or $\mathrm{OH} ; \mathrm{R}_{4}, \mathrm{R}_{6}, \mathrm{R}_{8}=\mathrm{H}$ or C-glycoside (for luteolin glycosides); $\mathrm{R}_{1}=\mathrm{H} ; \mathrm{R}_{3}, \mathrm{R}_{5}, \mathrm{R}_{7}=\mathrm{O}$-glycoside or $\mathrm{OH} ; \mathrm{R}_{2}, \mathrm{R}_{4}, \mathrm{R}_{6}, \mathrm{R}_{8}=\mathrm{H}$ or C-glycoside (for apigenin glycosides). 


\subsection{Animal Experiments}

The study was carried out on female Wistar rats 8 - 10 weeks old weighing 220 $250 \mathrm{~g}$ bred at the animal facility of the R.E. Kavetsky Institute of Experimental Pathology, Oncology and Radiobiology, National Academy of Sciences of Ukraine. The animals were housed at $20^{\circ} \mathrm{C}-23^{\circ} \mathrm{C}$ with free access to food and water under conventional conditions. All in vivo experiments were performed following the requirements of the regional Ethics Committee and compliance with the rules of work with laboratory animals.

Test agent was administered:

- intravenously (into the tail vein) at two different doses of $2.1 \mathrm{mg} / \mathrm{kg}$ and 4.3 $\mathrm{mg} / \mathrm{kg}$;

- orally (by gavage) at doses of $4.3 \mathrm{mg} / \mathrm{kg}$ and $17.0 \mathrm{mg} / \mathrm{kg}$.

Before the administration of the agent, each animal was weighed and the dose was calculated based on its body weight. After intravenous or oral administration of the test agent, the animals were anesthetized and blood was drawn from the portal vein into heparin tubes.

In the case of intravenous administration, the time points of examination were as follows: $0.167,0.33,0.67,1.0,2.0,4.0,8.0,14.25$ hours; in the case of oral administration-0.167, 0.33, 0.67, 1.0, 1.5, 2.0, 4.0, 6.0, 8.0, 12.0, 14.25 hours after administration of the test agent. For analysis of the data on each type of administration and each study period, blood plasma samples from 4 rats were used. Blood plasma of 5 rats without test agent administration was used as a negative control.

\subsection{HPLC Analysis of the Test Agent Plasma Concentrations}

For pharmacokinetic study, tricin was used as a marker of an active ingredient. This assumption is due to the high content of tricin (including in the form of glycosides) in the test agent and high antiviral activity compared to luteolin (the content of the latter in the test agent was recorded only in the form of glycosides). The content of apigenin is insignificant even taking into account its glycoside forms, especially since it is rapidly metabolized and eliminated from the body [28].

The quantitative assessment of the tricin content in the blood plasma of experimental animals at different terms of observation was carried out using HPLC analysis on a Waters UPLC PDA chromatograph, a $50 \mathrm{~mm} \times 2.1 \mathrm{~mm}$ column filled with an ACQUITY UPLC ${ }^{\circledR}$ BEH C18 sorbent, particle size $1.7 \mu \mathrm{m}$ [29] [30]. The mobile gradient phase was composed of acetonitrile- $0.1 \%$ formate acid. Detection was carried out at a wavelength of $350 \mathrm{~nm}$ (maximum absorption of tricin flavone).

\subsection{Mathematical Analysis of Test Agent Pharmacokinetics}

Data on the dynamics of changes in the concentration of tricin in biological samples were analyzed using mathematical modeling methods using compart- 
mental pharmacokinetic models: a two-compartment pharmacokinetic model for intravenous administration and a one-compartment pharmacokinetic model with absorption for oral administration.

Within the framework of a two-compartment pharmacokinetic model, the distribution of tricin in the central compartment is related to its distribution in the blood (and well-perfused tissues), and in the peripheral compartment-to the poorly perfused tissues. The kinetics of tricin distribution in the first $\left(C_{1}(t)\right)$ and second $\left(C_{2}(t)\right)$ compartments in case of a single intravenous bolus injection were described by the following system:

$$
\begin{aligned}
& C_{1}(t)=A_{1} * \exp (-\alpha * t)+B_{1} * \exp (-\beta * t) \\
& C_{2}(t)=A_{2} *[\exp (-\beta * t)-\exp (-\alpha * t)]
\end{aligned}
$$

where

$$
\begin{aligned}
& A_{1}=\frac{D *\left(\alpha-k_{21}\right)}{V_{1} *(\alpha-\beta)} ; \\
& B_{1}=\frac{D *\left(k_{21}-\beta\right)}{V_{1} *(\alpha-\beta)} ; \\
& \alpha=\left(k_{21}+k_{12}+k_{e l}\right) / 2+\operatorname{sqrt}\left[\left(k_{21}+k_{12}+k_{e l}\right)^{2} / 4-k_{e l} * k_{21}\right] \\
& \beta=\left(k_{21}+k_{12}+k_{e l}\right) / 2-\operatorname{sqrt}\left[\left(k_{21}+k_{12}+k_{e l}\right)^{2} / 4-k_{e l} * k_{21}\right] ; \\
& A_{2}=\frac{D * k_{12}}{V_{1} *(\alpha-\beta)} ; \\
& V_{s s}=V_{1} *\left(k_{12}+k_{21}\right) / k_{21}
\end{aligned}
$$

Parameters $k_{12}$ and $k_{21}$ reflect the processes of tricin redistribution between the first and second compartments; $k_{e}$-constant of elimination from the first compartment; $D$ is the dose of the test agent; $V_{1}$ is the apparent volume of tricin distribution, $V_{s s}$ is the stationary volume of distribution, $\chi$ is a parameter characterizing the accumulation of tricin in the second compartment.

Within the framework of a one-compartment pharmacokinetic model for oral administration, it was assumed that after absorption from the gastrointestinal tract, tricin is mainly distributed in the blood (and in tissues with proper blood supply), while its elimination from the blood occurs much faster than the penetration into poorly perfused organs and tissues. In this case, The kinetics of tricin distribution in the blood $\left(C_{1}(t)\right)$ was described by the following formula:

$$
\begin{aligned}
& C_{1}(t)=A *\left(\exp \left(-k_{e l} * t\right)-\exp \left(-k_{a} * t\right)\right) \\
& A=\frac{D}{V_{1}} * \frac{k_{a}}{k_{a}-k_{e l}}
\end{aligned}
$$

The parameter $k_{a}$ characterizes the rate of adsorption of tricin from the ga- 
strointestinal tract into the blood; $k_{e}$-elimination constant; D is the dose; $V_{1}$ is the apparent volume of distribution.

Model independent parameters (mean values and standard errors) for intravenous injection $\left(\alpha, \beta, A_{1}, B_{1}\right)$ and for oral administration $\left(A, k_{a}, k_{e l}\right)$ were determined from the best fit of Equations (1a) and (2) to corresponding experimental data using nonlinear regression analysis (math package Origin v. 9.5).

Mean values of model dependent parameters $\left(k_{21}, k_{12}, k_{e l}, V_{1}\right)$ for intravenous administration were determined from a system of algebraic Equations (1b). Standard errors for these parameters were calculated using the following formula [31]:

$$
\operatorname{SE}\left(m_{i}\right)=\operatorname{sqrt}\left(\sum_{j=1}^{4}\left(\frac{\partial F_{i}}{\partial p_{j}} * S E\left(p_{j}\right)\right)^{2}\right), i=1,2,3,4
$$

where

$$
\begin{aligned}
& p_{1}=\alpha ; p_{2}=\beta ; p_{3}=A_{1} ; p_{4}=B_{1} ; \\
& m_{1}=k_{21}=F_{1}\left(p_{1}, p_{2}, p_{3}, p_{4}\right) ; \\
& m_{2}=k_{12}=F_{2}\left(p_{1}, p_{2}, p_{3}, p_{4}\right) ; \\
& m_{3}=k_{e l}=F_{3}\left(p_{1}, p_{2}, p_{3}, p_{4}\right) ; \\
& m_{4}=V_{1}=F_{4}\left(p_{1}, p_{2}, p_{3}, p_{4}\right) ;
\end{aligned}
$$

$\operatorname{SE}\left(m_{i}\right)_{i=1,2,3,4}$-standard errors of corresponding model-dependent parameters;

$S E\left(p_{j}\right)_{j=1,2,3,4}$-standard errors of corresponding model-independent parameters.

According to the model-independent parameters, the following compartmental parameters of tricin pharmacokinetics were calculated:

- for intravenous administration-the half-life of the test agent $\left(t_{1 / 2, \alpha}\right)$, half-life $\left(t_{1 / 2, \beta}\right)$, mean residence time in blood plasma $(M R T)$, clearance $(C l)$ and apparent volume of distribution in the first compartment $\left(V_{1}\right)$ :

$$
\begin{aligned}
& M R T=A U M C_{\infty} / A U C_{\infty} \\
& C l=D / A U C_{\infty} \\
& t_{1 / 2, \alpha}=0.693 / \alpha \\
& t_{1 / 2, \beta}=0.693 / \beta \\
& V_{1}=D /\left(A_{1}+B_{1}\right)
\end{aligned}
$$

where

$$
\begin{aligned}
& A U C_{\infty}=A_{1} / \alpha+B_{1} / \beta ; \\
& A U M C_{\infty}=A_{1} / \alpha^{2}+B_{1} / \beta^{2} .
\end{aligned}
$$

- for oral administration-maximum concentration $\left(C_{\max }\right)$, time to reach maximum concentration $\left(t_{\max }\right)$, half-life $\left(T_{1 / 2}\right)$, mean residence time of the test agent in blood plasma $(M R T)$, clearance $(C I)$, and apparent volume of 
distribution $\left(V_{1}\right)$ :

$$
\begin{aligned}
& M R T=A U M C_{\infty} / A U C_{\infty} \\
& C l=D / A U C_{\infty} \\
& T_{1 / 2}=0.693 / k_{e l} \\
& V_{1}=D / A
\end{aligned}
$$

where

$$
\begin{aligned}
& A U C_{\infty}=A *\left(1 / k_{e l}-1 / k_{a}\right) ; \\
& A U M C_{\infty}=A *\left(1 / k_{e l}^{2}-1 / k_{a}^{2}\right) .
\end{aligned}
$$

- absolute bioavailability $\left(f_{a}\right)$ was determined by the ratio of the areas under the pharmacokinetic curve for oral $\left(A U C_{\text {peros }}\right)$ and intravenous $\left(A U C_{i v}\right)$ administration according to the formula:

$$
f_{a}=\frac{A U C_{\text {peros }} * D_{i v}}{A U C_{i v} * D_{\text {peros }}}
$$

\subsection{Statistical Analysis}

For the statistical analysis of the results, descriptive statistics, Student's and Man-Whitney criteria were used. The difference between the compared indices $\mathrm{p}$ $<0.05$ was considered statistically significant. All data are expressed as mean \pm standard error (SE).

\section{Results and Discussion}

\subsection{Pharmacokinetics of Tricin after Its Single Intravenous Bolus Injection}

The study has shown that the kinetics of tricin distribution in the blood plasma of rats after its single intravenous injection has a pronounced two-phase character (for both doses of the test agent) and is well described by formula (1) (Figure 2).

The values of the model-independent parameters of tricin pharmacokinetics for both investigated doses are presented in Table 1. Analysis of these parameters showed that tricin is distributed rather quickly in the body of animals and is relatively slowly excreted. In particular, if the test agent is administered at a dose of $2.1 \mathrm{mg} / \mathrm{kg}$, its distribution half-life $\left(t_{1 / 2, \alpha}\right)$ is less than 10 minutes, while its elimination half-life $\left(t_{1 / 2, \beta}\right)$ is more than 2 hours.

The distribution and elimination of tricin after administration of the test agent at a dose of $4.3 \mathrm{mg} / \mathrm{kg}$ significantly differs from these for a lower dose. A twofold increase in the dose of the test agent does not lead to an increase in the concentration of tricin in the blood plasma (which would be expected if there was a linear dependence of pharmacokinetics on dose). So the area under the pharmacokinetic curve after administration of tricin at a dose of $4.3 \mathrm{mg} / \mathrm{kg}$ and a dose of $2.1 \mathrm{mg} / \mathrm{kg}$ is practically the same. Meanwhile, the mean residence time (MRT) of tricin at a higher dose of the test agent is $20 \%$ less than at a lower dose $(\mathrm{p}<0.05)$. 

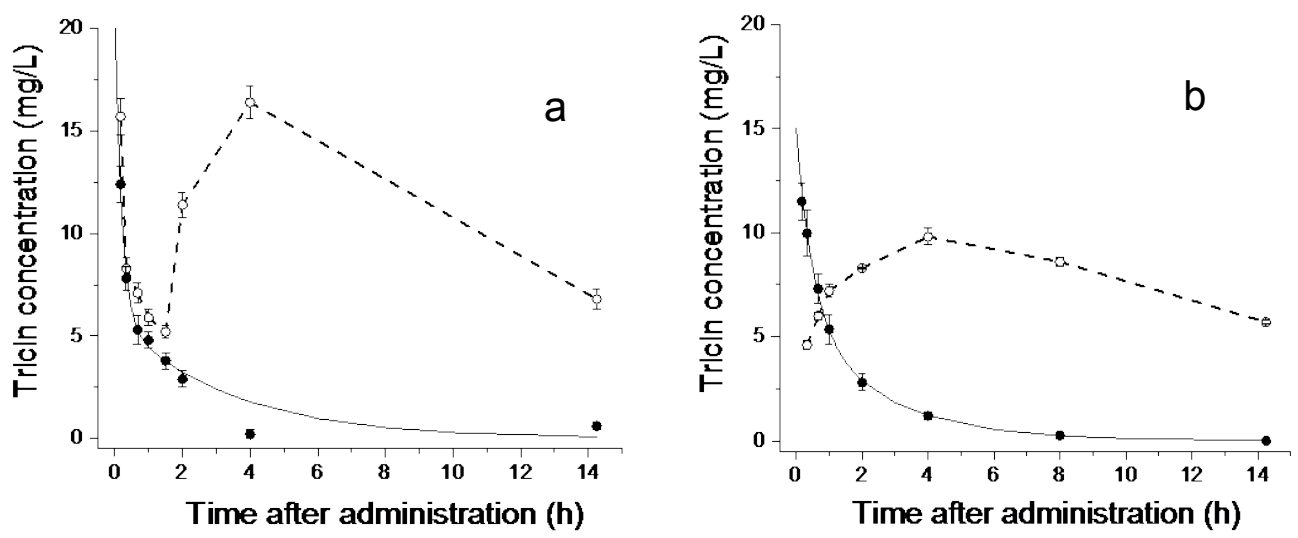

Figure 2. Tricin concentration versus time after intravenous bolus injection of the agent at a dose of $2.1 \mathrm{mg} / \mathrm{kg}$ (a) and $4.3 \mathrm{mg} / \mathrm{kg}$ (b). Solid lines-theoretical pharmacokinetic curves obtained as a result of the best fit of experimental concentrations in plasma (indicated by black circles) by formula (1); open circles-experimental concentrations in blood cells.

Table 1. Pharmacokinetic parameters of tricin after single intravenous injection of the test agent to Wistar rats.

\begin{tabular}{|c|c|c|}
\hline \multirow{2}{*}{ Pharmacokinetic parameters } & \multicolumn{2}{|c|}{ Dose of the test agent $(\mathrm{mg} / \mathrm{kg})$} \\
\hline & 2.1 & 4.3 \\
\hline \multicolumn{3}{|c|}{ Model-independent parameters } \\
\hline$A_{1}(\mathrm{mg} / \mathrm{L})$ & $15.0 \pm 2.4$ & $9.0 \pm 0.4$ \\
\hline$B_{1}(\mathrm{mg} / \mathrm{L})$ & $5.9 \pm 0.5$ & $6.0 \pm 0.3$ \\
\hline$\alpha\left(\mathrm{h}^{-1}\right)$ & $5.1 \pm 0.4$ & $1.93 \pm 0.06$ \\
\hline$\beta\left(\mathrm{h}^{-1}\right)$ & $0.3 \pm 0.02$ & $0.4 \pm 0.02$ \\
\hline$A U C_{\infty}\left(\mathrm{mg}^{*} \mathrm{~h} / \mathrm{L}\right)$ & $22.6 \pm 2.3$ & $18.1 \pm 1.5$ \\
\hline$t_{1 / 2 . \alpha}(\mathrm{h})$ & $0.136 \pm 0.011$ & $0.36 \pm 0.01$ \\
\hline$t_{1 / 2 . \beta}(\mathrm{h})$ & $2.3 \pm 0.15$ & $1.73 \pm 0.09$ \\
\hline$C l(\mathrm{~L} / \mathrm{h})$ & 0.022 & 0.052 \\
\hline$M R T(\mathrm{~h})$ & 2.93 & 2.2 \\
\hline$V_{1}(\mathrm{~L})$ & $0.024 \pm 0.004$ & $0.067 \pm 0.005$ \\
\hline \multicolumn{3}{|c|}{ Model-dependent parameters } \\
\hline$K_{e l}\left(\mathrm{~h}^{-1}\right)$ & $0.9 \pm 0.1$ & $0.77 \pm 0.03$ \\
\hline$K_{12}\left(\mathrm{~h}^{-1}\right)$ & $2.82 \pm 0.4$ & $0.56 \pm 0.02$ \\
\hline$K_{21}\left(\mathrm{~h}^{-1}\right)$ & $1.66 \pm 0.3$ & $1.0 \pm 0.06$ \\
\hline$x$ & 0.52 & 0.24 \\
\hline$V_{1}(\mathrm{~L})$ & $0.024 \pm 0.004$ & $0.067 \pm 0.005$ \\
\hline$V_{s s}(\mathrm{~L})$ & 0.065 & 0.105 \\
\hline
\end{tabular}

Noteworthy is the almost threefold statistically significant increase in the apparent volume of distribution and half-distribution of tricin in the first (blood-related) compartment after its administration at a dose of $4.3 \mathrm{mg} / \mathrm{kg}$ 
(compared to a dose of $2.1 \mathrm{mg} / \mathrm{kg}$ ). This difference may be partly due to the different volumes of the test agent administered, which was $125 \mu \mathrm{l}$ at a dose of 4.3 $\mathrm{mg} / \mathrm{kg}$ and was 2 times higher than the volume of distribution of tricin at a dose of $2.1 \mathrm{mg} / \mathrm{kg}$. To clarify the reasons for the disturbance of the linear dependence of pharmacokinetics on the dose, model-dependent pharmacokinetic parameters were analyzed (Table 1 ).

After the test agent administration at a dose of $2.1 \mathrm{mg} / \mathrm{kg}$, the rate of transition of tricin from the first compartment (blood plasma) to the second compartment $\left(K_{12}\right)$ was almost 5 times higher compared to the corresponding index for a dose of $4.3 \mathrm{mg} / \mathrm{kg}$. Even though the rate of reverse transition of tricin from the second compartment $\left(K_{21}\right)$ to the first one was $66 \%$ higher $(\mathrm{p}<0.05)$ for a dose of $2.1 \mathrm{mg} / \mathrm{kg}$ than for a dose of $4.3 \mathrm{mg} / \mathrm{kg}$, the pharmacokinetic parameter of tricin accumulation in the second compartment $\chi$ for a lower dose is almost twice higher than the corresponding index for a larger dose. The high rate of tricin transfer (at a dose of $2.1 \mathrm{mg} / \mathrm{kg}$ ) into the second compartment determines high levels of its accumulation in it.

The kinetics of tricin distribution in the second compartment (prediction of the pharmacokinetic model) for both doses is bell-shaped: the accumulation phase is replaced by the elimination phase. The maximum level of tricin accumulation at a dose of $2.1 \mathrm{mg} / \mathrm{kg}$ in the second compartment is approximately 3 times higher than that at a higher dose. The analysis of the model-dependent parameters of tricin indicates that the tissue structure of the second compartment (peripheral concerning blood plasma) and its volume differ significantly between the studied doses. In particular, after administration of the test agent at a dose of $2.1 \mathrm{mg} / \mathrm{kg}$, tricin is distributed to a greater extent in the bloodstream (first compartment), as well as in those cellular systems that are characterized by an extremely high level of bioavailability. Such systems can include blood cells, which represent mainly the second pharmacokinetic compartment. The small volume of the injected test agent at the indicated dose does not allow for its penetration into organs and tissues, which are characterized by lower availability compared to blood cells. In this case, the accumulation of tricin in organs can occur via secondary adsorption due to its release from blood cells located in a tissue.

A fundamentally different situation occurs when the test agent is administered at a dose of $4.3 \mathrm{mg} / \mathrm{kg}$. Twice higher volume of the administered test agent (in comparison with the lower dose) provides 2.8 times higher volume of its distribution in the animal body. At a dose of $4.3 \mathrm{mg} / \mathrm{kg}$, tissues with a lower bioavailability (forming the second distribution compartment) are characterized by a twice lower level of its accumulation as compared to this index in the second compartment after administration of the test agent at a dose of $2.1 \mathrm{mg} / \mathrm{kg}$.

This conclusion, based on the analysis of the pharmacokinetic parameters of tricin, is fully confirmed by the results of a study of tricin distribution in blood cells (Figure 1). 
The kinetics of tricin distribution in blood cells after agent administration at a dose of $4.3 \mathrm{mg} / \mathrm{kg}$ demonstrates standard one-peak character: the accumulation phase is replaced by the phase of its elimination from the cells. After the administration of the agent at a dose of $2.1 \mathrm{mg} / \mathrm{kg}$, fundamentally different kinetics is observed. The tricin distribution in blood cells demonstrates two-peak kinetics, reflecting the existence of two phases of its accumulation, significantly spaced in time. The first phase includes a rapid and significant accumulation of tricin (ensuring the achievement of tricin concentrations in blood cells above that in plasma) during the first 10 minutes after its intravenous administration, followed by a progressive decrease in its content within an hour. The rates of accumulation of tricin by blood cells and excretion from them at the second phase are significantly slower than at the first.

One should note the high availability of blood cells to tricin, regardless of the dose administered. In particular, the area under the kinetic curve of tricin distribution in blood cells ( $\left.A U C_{\text {blood cell }}\right)$ for both doses is significantly higher than that for tricin plasma kinetics (Table 2), which indicates a significantly higher level of the agent accumulation in this cellular system compared to blood plasma.

\subsection{Pharmacokinetics of Tricin after a Single Oral Administration}

The study has shown that the kinetics of tricin distribution in the blood plasma of rats after a single oral administration of the test agent at both doses is of a classical nature: the phase of absorption into the blood is replaced by the phase of elimination (Figure 3).

Analysis of model-independent parameters of pharmacokinetics showed that, regardless of the test agent dose, tricin is rapidly absorbed from the gastrointestinal tract of animals, reaching maximum plasma concentrations already in 20 minutes after administration (Table 3 ). The adsorption rate of tricin is very high, and significantly and nonlinearly (relatively to the dose) increases with an increase in the dose of the test agent: the maximum value of the tricin concentration at a dose of $17.0 \mathrm{mg} / \mathrm{kg}$ is approximately 20 times higher than that at a dose of $4.3 \mathrm{mg} / \mathrm{kg}$. Meanwhile, tricin is excreted from the body very slowly and the rate of this process does not depend on the dose.

Analysis of the pharmacokinetics of tricin after oral administration of the test agent at a dose of $4.3 \mathrm{mg} / \mathrm{kg}$ showed that its distribution in the body is well described by a single-compartment pharmacokinetic model with absorption. As it

Table 2. The area under the kinetic curve of tricin distribution in blood cells after intravenous bolus injection of the test agent.

\begin{tabular}{ccc}
\hline \multirow{2}{*}{ Pharmacokinetic parameters } & \multicolumn{2}{c}{ Dose of the test agent $(\mathrm{mg} / \mathrm{kg})$} \\
\cline { 2 - 3 } & 2.1 & 4.3 \\
\hline$A U C_{\text {blood cell }}(\mathrm{mg} \cdot \mathrm{h}) / \mathrm{L}$ & $161.7 \pm 12.8$ & $112.2 \pm 8.7$ \\
$A U C_{\text {plasma }}(\mathrm{mg} \cdot \mathrm{h}) / \mathrm{L}$ & $22.6 \pm 2.3$ & $18.1 \pm 1.5$ \\
\hline
\end{tabular}


Table 3. Pharmacokinetic parameters of tricin after single oral administration of the test agent to Wistar rats.

\begin{tabular}{|c|c|c|}
\hline \multirow{2}{*}{ Pharmacokinetic parameters } & \multicolumn{2}{|c|}{ Dose of the test agent $(\mathrm{mg} / \mathrm{kg})$} \\
\hline & 4.3 & 17.0 \\
\hline \multicolumn{3}{|c|}{ Model-independent parameters } \\
\hline$C_{\max }(\mathrm{mg} / \mathrm{L})$ & $4.3 \pm 0.4$ & $84.5 \pm 1.2$ \\
\hline$t_{\max }(h)$ & $0.33 \pm 0.06$ & $0.33 \pm 0.04$ \\
\hline$K_{e l}\left(\mathrm{~h}^{-1}\right)$ & $0.3 \pm 0.04$ & $0.27 \pm 0.03$ \\
\hline$M R T(\mathrm{~h})$ & 3.36 & 1.85 \\
\hline$A U C(\mathrm{mg} \cdot \mathrm{h} / \mathrm{L})$ & $14.2 \pm 1.8$ & $59.4 \pm 6.4$ \\
\hline \multicolumn{3}{|c|}{ Model-dependent parameters } \\
\hline$A(\mathrm{mg} / \mathrm{L})$ & $4.3 \pm 0.25$ & \\
\hline$K_{e l}\left(\mathrm{~h}^{-1}\right)$ & $0.3 \pm 0.04$ & \\
\hline$K_{a}\left(\mathrm{~h}^{-1}\right)$ & $25.3 \pm 4.0$ & \\
\hline$T_{1 / 2}(\mathrm{~h})$ & $2.31 \pm 0.15$ & \\
\hline$C l(\mathrm{~L} / \mathrm{h})$ & 0,072 & \\
\hline$V_{1}(\mathrm{~L})$ & $0.24 \pm 0.01$ & \\
\hline
\end{tabular}

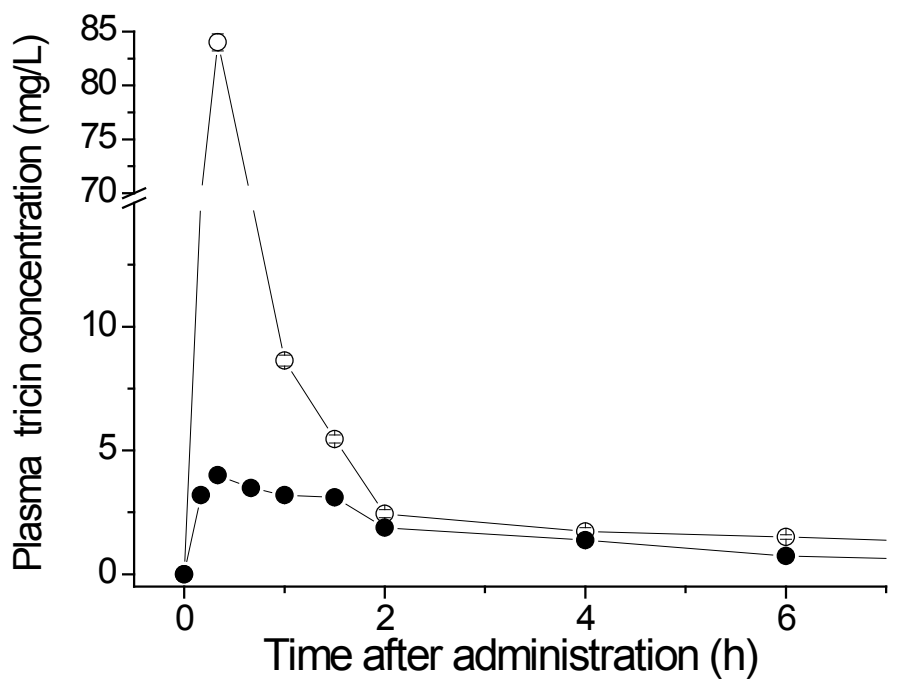

Figure 3. Plasma tricin concentration versus time after a single oral administration of the agent at a dose of $4.3 \mathrm{mg} / \mathrm{kg}$ (black circles) and $17.0 \mathrm{mg} / \mathrm{kg}$ (open circles).

seen in Table 3 the adsorption rate of tricin is almost 100 times higher than the rate of its elimination from the body. One should note the significant volume of its distribution after oral administration, which is almost 3 times higher than the volume of distribution after intravenous administration of the test agent at the same dose. The latter fact points to the advantages of the oral route of administration of the test agent.

The study has shown that the pharmacokinetics of tricin after administration at a dose of $17.0 \mathrm{mg} / \mathrm{kg}$ is not described by either a single-compartment or 
two-compartment pharmacokinetic models and requires more complex methods of mathematical analysis. It is important to note that, despite the nonlinear nature of the dose-dependent distribution of tricin, the area under the pharmacokinetic curve (which determines its bioavailability) after oral administration is linearly dependent on the dose: 4 -fold increase of the dose of the test agent leads to 4 -fold increase of the area under the pharmacokinetic curve (Table 3). When the test agent was administered intravenously, such a linear relationship was not observed. This difference between intravenous and oral administration of the test agent also indicates the advantages of the oral route of administration.

It is known that bioavailability of the total majority of drugs is the main index characterizing the quantity of the agent at the site of its pharmacological action. In the case of intravenous administration, the agent enters the bloodstream. If extravascular routes of administration are used, (such as oral, intramuscular, subcutaneous ones), the agent passes through several biological membranes (mucous membrane of the stomach, liver, muscles, etc.) and only part of it enters the systemic circulation. The pharmacological action of the drug largely depends on its amount of entering circulation. This index characterizes the bioavailability of the agent. When it is administered intravenously, bioavailability is taken as $100 \%$. With other routes of administration, bioavailability rarely reaches $100 \%$. The bioavailability of a medicinal substance can be influenced by the route of administration of the drug, the dose, the individual characteristics of the organism, and biopharmaceutical factors (such as dosage form, its composition, features of the production technology of the agent) also have a significant impact.

Table 4 shows the results of determining the bioavailability of tricin after a single oral administration at a dose of $4.3 \mathrm{mg} / \mathrm{kg}$ (equal to the intravenous dose) and a dose of $17.0 \mathrm{mg} / \mathrm{kg}$. The bioavailability of the last dose was assessed taking into account the dose differences according to the formula (5). Upon a single oral administration tricin is characterized by a high bioavailability-about $80 \%$ on average, and by a low variability in bioavailability at different doses of the test agent administration.

So, our study has shown that the pharmacokinetics of tricin administered orally is characterized by a high rate of absorption from the gastrointestinal tract into the blood and rather slow elimination, which leads to a large volume of distribution in the body and a fairly high bioavailability. If it is administered orally, but not by the intravenous route, a linear dependence of the area under the pharmacokinetics curve on the dose of the administered agent is observed.

Table 4. Bioavailability of tricin after single oral administration of the test agent.

\begin{tabular}{cccc}
\hline \multirow{2}{*}{ Pharmacokinetic parameters } & \multicolumn{2}{c}{ Intravenous injection at a dose } & \multicolumn{2}{c}{ Oral administration at doses } \\
\cline { 2 - 4 } & $4.3 \mathrm{mg} / \mathrm{kg}$ & $4.3 \mathrm{mg} / \mathrm{kg}$ & $17.0 \mathrm{mg} / \mathrm{kg}$ \\
\hline$A U C(\mathrm{mg} \cdot \mathrm{h} / \mathrm{L})$ & $18.1 \pm 1.5$ & $14.2 \pm 1.3$ & $59.4 \pm 6.1$ \\
$f_{a}(\%)$ & 100.0 & 77.8 & 82.0 \\
\hline
\end{tabular}




\section{Conclusions}

The pharmacokinetics of tricin after a single intravenous administration of an ethanol extract of the Calamagrostis Adans and Deschampsia Beauv plants has a pronounced biphasic character and is well described by a two-compartment pharmacokinetic model. After bolus injection, dose dependence of tricin pharmacokinetics is non-linear, which is most likely due to both the small volume of the drug administered and the high availability of blood cells to tricin, regardless of the dose administered. In particular, the area under the kinetic curve of tricin distribution in blood cells for both studied doses was more than 6 times higher than that for tricin plasma kinetics. The high tropism of tricine to blood cells prolongs its residence time in the body and can promote its accumulation in organs and tissues with good blood supply and significantly improve the pharmacological action of this agent.

Tricin after a single oral administration of an ethanol extract of the plants $\mathrm{Ca}$ lamagrostis Adans and Deschampsia Beauv is characterized by high adsorption rate which is almost 100 times higher than the rate of its elimination from the body. This causes the significant volume of tricin distribution after oral administration (which is almost 3 times higher than the volume of distribution after intravenous administration of the test agent at the same dose), and relatively high bioavailability, which was over $77 \%$. Thus, high bioavailability, a large volume of distribution (compared to intravenous administration), as well as a linear dependence of the area under the pharmacokinetics curve on a dose, indicates the advantages of the oral route of administration over the intravenous route.

\section{Acknowledgements}

This study was supported by a research grant from SMC Ecopharm Ltd. The authors also thank Dr. Maria Soldatkina for the fruitful discussion and help in editing English text.

\section{Conflicts of Interest}

The authors declare no conflicts of interest associated with this manuscript.

\section{References}

[1] Shafi, W., Mansoor, S., Jan, S., Singh, D.B., Kazi, M., Raish., M., Alwadei, M., Mir, J.I. and Ahmad, P. (2019) Variability in Catechin and Rutin Contents and Their Antioxidant Potential in Diverse Apple Genotypes. Molecules, 24, Article No. 943. https://www.mdpi.com/1420-3049/24/5/943 https://doi.org/10.3390/molecules24050943

[2] Maleki, S.J., Crespo, J.F. and Cabanillas, B. (2019) Anti-Inflammatory Effects of Flavonoids. Food Chemistry, 299, Article ID: 125124. https://www.sciencedirect.com/science/article/abs/pii/S0308814619312300?via\%3Di hub https://doi.org/10.1016/j.foodchem.2019.125124

[3] Lim, H., Heo, M.Y. and Kim, H.P. (2019) Flavonoids: Broad Spectrum Agents on 
Chronic Inflammation. Biomolecules \& Therapeutics, 27, 241-253.

http://www.biomolther.org/journal/view.html?volume=27\&number=3\&spage $=241$

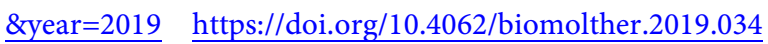

[4] Ginwala, R., Bhavsar, R., Chigbu, D.I., Jain, P. and Khan, Z.K. (2019) Potential Role of Flavonoids in Treating Chronic Inflammatory Diseases with a Special Focus on the Anti-Inflammatory Activity of Apigenin. Antioxidants, 8, 35.

https://www.mdpi.com/2076-3921/8/2/35

https://doi.org/10.3390/antiox8020035

[5] Lalani, S. and Poh, C.L. (2020) Flavonoids as Antiviral Agents for Enterovirus A71 (EV-A71). Viruses, 12, 184. https://www.mdpi.com/1999-4915/12/2/184 https://doi.org/10.3390/v12020184

[6] Zakaryan, H., Arabyan, E., Oo, A. and Zandi, K. (2017) Flavonoids: Promising Natural Compounds against Viral Infections. Archives of Virology, 162, 2539-2551. https://doi.org/10.1007/s00705-017-3417-y

[7] Kikuchi, H., Yuan, B., Hu, X. and Okazaki, M. (2019) Chemopreventive and Anticancer Activity of Flavonoids and its Possibility for Clinical Use by Combining with Conventional Chemotherapeutic Agents. American Journal of Cancer Research, 9 , 1517-1535.

[8] Solyanik, G.I., Pyaskovskaya, O.M. and Rodionova, N.K. (2014) Correction of Cancer-Related Anemia with Oxyresveratrol. In: Winter, L.H., Ed., Paraneoplastic Syndromes: Symptoms, Diagnosis and Treatment, Nova Publisher Inc., New York, 163-200.

[9] Pyaskovskaya, O., Shalamay, A., Rodionova, N. and Yakshibaeva, Yu. (2017) Correction of Tumor-Associated Thrombocytopenia by Quercetin. In: Watanabe, H.S., Ed., Horizons in Cancer Research, Nova Publisher Inc., New York, 193-208.

[10] Rees, A., Dodd, G.F. and Spencer, J.P.E. (2018) The Effects of Flavonoids on Cardiovascular Health: A Review of Human Intervention Trials and Implications for Cerebrovascular Function. Nutrients, 10, 1852. https://doi.org/10.3390/nu10121852 https://www.mdpi.com/2072-6643/10/12/1852

[11] Hossain, M.K., Dayem, A.A., Yingfu, J.H., Han, J., Yin, Y., Kim, K., Saha, S.K., Yang, G.-M, Choi, H.Y. and Cho, S.-G. (2016) Molecular Mechanisms of the Anti-Obesity and Anti-Diabetic Properties of Flavonoids. International Journal of Molecular Science, 17, 569. https://www.mdpi.com/1422-0067/17/4/569 https://doi.org/10.3390/ijms17040569

[12] Li, M., Pu, Y., Yoo, C.G. and Ragauskas, A.J. (2016) The Occurrence of Tricin and Its Derivatives in Plants. Green Chemistry, 18, 1439-1454. https://doi.org/10.1039/C5GC03062E

[13] Jiang, B., Song, J. and Jin, Y. (2020) A Flavonoid Monomer Tricin in Gramineous Plants: Metabolism, Bio/Chemosynthesis, Biological Properties, and Toxicology. Food Chem, 320, Article ID: 126617. https://doi.org/10.1016/j.foodchem.2020.126617 https://www.sciencedirect.com/science/article/abs/pii/S0308814620304799

[14] Sakai, A., Watanabe, K., Koketsu, M., Akuzawa, K., Yamada, R., Li, Zh., Sadanari, H., Matsubara, K. and Murayama, T. (2008) Anti-Human Cytomegalovirus Activity of Constituents from Sasa Albo-Marginata (Kumazasa in Japan). Antiviral Chemistry and Chemotherapy, 19, 125-132. https://doi.org/10.1177\%2F095632020801900303

[15] Akuzawa, K., Yamada, R., Li, Z., Li, Y, Sadanari, H., Matsubara, K., Watanabe, K., Koketsu, M., Tuchida, Y. and Murayama, T. (2011) Inhibitory Effects of Tricin De- 
rivative from Sasa albo-marginata on Replication of Human Cytomegalovirus. Antiviral Research, 91, 96-303. https://doi.org/10.1016/j.antiviral.2011.06.014

[16] Murayama, T., Li, Y., Takahashi, T., Yamada, R., Matsubara, K., Tuchida, Yu., Li, Zh. and Sadanari, H. (2012) Anti-Cytomegalovirus Effects of Tricin are Dependent on CXCL11. Microbes and Infection, 14, 1086-1092.

https://doi.org/10.1016/j.micinf.2012.05.017

[17] Sadanari, H., Fujimoto, K.J., Sugihara, Y., Ishida, T., Takemoto, M., Daikoku, T. and Murayama, T. (2018) The Anti-Human Cytomegalovirus Drug Tricin Inhibits Cyclin-Dependent Kinase 9. FEBS Open Bio, 8, 646-654. https://doi.org/10.1002/2211-5463.12398

[18] Li, H., Zhou, C.X., Pan, Y., Gao, X., Wu, X., Bai, H., Zhou, L., Zhang, S., Shi, Sh., Luo, J., Xu, J., Chen, L., Zheng, X. and Zhao, Y. (2005) Evaluation of Antiviral Activity of Compounds Isolated from Ranunculus sieboldii and Ranunculus sceleratus. Planta Medica, 71, 1128-1133. https://doi.org/10.1055/s-2005-873169

[19] Yazawa, K., Kurokawa, M., Obuchi, M., Li, Y., Yamada, R., Sadanari, H., Matsubara, K., Watanabe, K., Mamoru K., Tuchida, Yu. and Murayama, T. (2011) Anti-Influenza Virus Activity of Tricin, 4',5,7-trihydroxy-3',5'-dimethoxyflavone. Antiviral Chemistry and Chemotherapy, 22, 1-11. https://doi.org/10.3851\%2FIMP1782

https://journals.sagepub.com/doi/full/10.3851/IMP1782

[20] Ajitha, M.J., Mohanlal, S., Suresh, C.H. and Jayalekshmy, A. (2012) DPPH Radical Scavenging Activity of Tricin and Its Conjugates Isolated from "Njavara" Rice Bran: A Density Functional Theory Study. Journal of Agricultural and Food Chemistry, 60, 3693-3699. https://doi.org/10.1021/jf204826e

[21] Verschoyle, R.D., Greaves, P., Cai, H., Borkhardt, A., Broggini, M., D’Incalci, M., Riccio, E., Doppalapudi, R., Kapetanovic, I.M., Steward, W.P. and Gescher, A.J. (2006) Preliminary Safety Evaluation of the Putative Cancer Chemopreventive Agent Tricin, a Naturally Occurring Flavone. Cancer Chemotherapy and Pharmacology, 57, 1-6. https://doi.org/10.1007/s00280-005-0039-y

[22] Palchykovska, L.G., Vasylchenko, O.V., Platonov, M.O., Starosyla, D.B., Porva, J. I., Rymar, S.J., Atamaniuk, V.P., Samijlenko, S.P. and Rybalko, S.L. (2013) Antiviral Properties of Plant Flavonoids Inhibitors of DNA and RNA Synthesis. Biopolymers and Cell, 29, 150-156. http://dx.doi.org/10.7124/bc.000813

[23] Kaminsky, V., Chernyshov, V., Grynevych, O., Benyuk, V., Kornatskaya, A., Shalko, M., Usevich, I., Revenko, O., Shepetko, M. and Solomakha, L. (2017) Proteflazid ${ }^{\circ}$ and Local Immunity in Diseases Caused by Human Papillomavirus, Herpesvirus and Mixed Urogenital Infections. Polish Medical Journal, 42, 110-115.

[24] Povnitsa, O.Y., Biliavska, L.O., Pankivska, Yu.B., Naumenko, K.S., Zelena, L.B., Zagorodnya, S.D. and Atamanyuk, V.P. (2018) Anti-Adenoviral Activity of Neoflazid in Vitro. Journal of Microbiology, 80, 98-109. https://doi.org/10.15407/microbiolj80.05.098

[25] Toutain, P. L. and Bousquet-Mélou, A. (2004) Bioavailability and Its Assessment. Journal of Veterinary Pharmacology and Therapeutics, 27, 455-466. https://doi.org/10.1111/j.1365-2885.2004.00604.x

[26] Amidon, G.L., Lennernas, H., Shah, V.P. and Crison, J. R. (1995) A Theoretical Basis for a Biopharmaceutic Drug Classification: The Correlation of in Vitro Drug Product Dissolution and In Vivo Bioavailability. Pharmaceutical Research, 12, 413-420. https://doi.org/10.1023/A:1016212804288

[27] Cheng, Y., Wang, Z.H., Ding, S.Z. and Li, J.C. (2015) Determination and Correlation of the Solubility of Tricin in Water and Ethanol Mixtures. The Journal of 
Chemical Thermodynamics, 89, 89-92. https://doi.org/10.1016/j.jct.2015.04.037

[28] Tang, D., Chen, K., Huang, L. and Li, J. (2017) Pharmacokinetic Properties and Drug Interactions of Apigenin, a Natural Flavone. E Expert Opinion on Drug Metabolism \& Toxicology, 13, 323-330.

https://doi.org/10.1080/17425255.2017.1251903

[29] Cai, H., Verschoyle, R.D., Steward, W.R. and Gescher, A.J. (2003) Determination of the Flavone Tricin in Human Plasma by High Performance Liquid Chromatography. Biomedical Chromatography, 17, 435-439. https://doi.org/10.1002/bmc.260

[30] Cai, H., Steward, W.P. and Gescher, A.J. (2005) Determination of the Putative Cancer Chemopreventive Flavone Tricin in Plasma and Tissue of Mice by HPLC with UV-Visible Detection. Biomedical Chromatography, 19, 518-522.

https://doi.org/10.1002/bmc.473

[31] Taylor, J.R. (1997) An Introduction to Error Analysis: The Study of Uncertainties in Physical Measurements. 2nd Edition, University Science Books, Sausalito. 